\title{
Reflexão cristológico-trinitária Contribuições para a compreensão da experiência religiosa e da espiritualidade como aproximações para o diálogo inter-religioso
}

Ismael Souza

\section{Resumo}

A contemporaneidade apresenta uma cultura plurirreligiosa. Como no âmago de todas as religiões encontra-se a experiência religiosa, este é o solo onde se dará o diálogo inter-religioso. No terreno movediço da experiência religiosa se tornam clarificadoras a experiência religiosa, a teologia e a espiritualidade de Jesus de Nazaré. O presente artigo apresenta a importância da reflexão da teologia cristã para compreensão da experiência religiosa e da espiritualidade como aproximações para o diálogo inter-religioso.

Palavras-chave: Diálogo Inter-religioso, Espiritualidade, Experiência Religiosa, Jesus de Nazaré, Trindade.

\section{Abstract}

In these days the multireligious culture presents itself. How inside of all religions we can find the religious experience, and this is the base where we can see the interreligious dialogue. In the camp of the religion experience becames clarifying the religious experience itself, the theology and the spirituality of Jesus of Nazareth. This article presents the importance of the christian theology reflection to comprehend the religion experience and the spirituality as the interreligious dialogue approach. 
Keywords: Interreligious Dialogue, Spirituality, Religious Experience, Jesus of Nazareth, Trinity.

\section{Introdução}

Na contemporaneidade é notória a observação dos processos de globalização, secularização, pluralização e queda das utopias, principalmente no mundo ocidental. Cada um destes fenômenos, com suas características, influenciam o ser humano em seus ideais, pensamentos, aspirações e ações.

Com o desdobramento destes e outros processos, nada fica de fora de possíveis transformações. E neste terreno instável encontram-se também a religião, a espiritualidade e as experiências religiosas, temas da nossa reflexão. Assim, hoje observamos o retorno ao religioso tendo culminância na cultura plurireligiosa hodierna.

Desde seu surgimento a fé cristã, levando em consideração cada período da história, foi e continua a ser interpelada e esta fé necessita responder de forma coerente e significativa aqueles (as) que a ela perguntam. Desta forma, conhecer o seu próprio tempo é necessário para que o cristão possa apresentar a fé em Jesus Cristo de forma contextualizada e coerente para seus contemporâneos. Porém, esta postura da fé cristã torna-se mais complexa e desafiadora devido a multiplicidade de experiências religiosas e diversas espiritualidades que alegam genuinidade, autenticidade e reconhecimento de suas expressões.

Com a consciência madura, o cristianismo aceita a existência da realidade mística em outras religiões, mas estas experiências necessitam de olhar investido de discernimento, mesmo no cristianismo. Pois, a experiência religiosa não se encerra em si mesma, mas encontra-se em íntimo relacionamento com o sentido da vida dado pela religião sendo expressa em práticas vivenciais, ou seja, na espiritualidade, que é exercida no âmbito da sociedade podendo trazer as mais variadas consequências.

Acreditando que é a partir desta interação presente em todas as religiões que ocorrerá o diálogo inter-religioso, não para decidir qual é a religião verdadeira, mas mutuamente dialogar tendo como objetivo o que é melhor para o ser humano se tornar mais humano e ajudá-lo a olhar com mais seriedade o sentido último da sua existência. Aqui se revelará o que é verdadeiro! ${ }^{1} \mathrm{E}$ deste

${ }^{1}$ Cf. KÜNG, Hans. Teologia a caminho: fundamentação para o diálogo ecumênico. São Paulo: Paulinas, 1999, p. 261-291. 
diálogo, de forma recíproca, observar os desafios e contribuições presentes nas diversas experiências religiosas, espiritualidades e religiões.

Imbuído deste espírito, apresenta-se aqui elementos da reflexão cristológico-trinitária como contribuições para compreensão da experiência religiosa e da espiritualidade como aproximações para o diálogo inter-religioso.

\section{A experiência do absoluto e a busca do sentido da vida}

Na experiência religiosa encontra-se, amalgamada, a experiência do absoluto $^{2}$ e a busca do sentido da vida ${ }^{3}$. Fundamentado em Josef Sudbrack, entende-se aqui, como "experiência religiosa" o que o referido autor chama de "mística" ou como "experiência do absoluto", ou seja, experiência autêntica de Deus. Porém, existem experiências semelhantes em todas as religiões, contudo nelas existem diferenças, encontros e divergências do modo como são entendidas. Desta forma, torna-se difícil uma definição genérica do termo. Entendendo-se que "a mística trata do sentido da vida"4 sendo este sentido dado pelo quadro interpretativo da religião, ${ }^{5}$ cada pessoa carrega para esta experiência e seu desdobramento, sua própria compreensão e postura que possui diante da vida. ${ }^{6}$ Estando, intimamente em relacionamento, a sedimentação de toda experiência humana, a experiência e conhecimento que se julga ter do absoluto, culminando numa expressão de práxis vivencial, isto é, numa espiritualidade ${ }^{7}$. Sudbrack insiste na existência da realidade mística, mesmo no entendimento cristão, fora da comunidade cristã como, por exemplo, na religiosidade asiática oriental. Pois, mesmo em outra religião, quando isso ocorre, só pode acontecer porque só existe um único Deus. ${ }^{8}$ Neste contexto, existe uma advertência que, "quando mergulhamos nas experiências religiosas mais profundas, nós nos movimentamos efetivamente numa passagem estreita entre a verdade e o engano." Assim, a busca e estas experiências, também no cristianismo, necessitam de

\footnotetext{
${ }^{2}$ Cf. SUDBRACK, Josef. Mística: a busca do sentido e a experiência do absoluto. São Paulo: Loyola, 2007, p.17.

${ }^{3}$ Cf. Ibid., p. 11.

${ }^{4}$ Ibid., p. 11.

${ }^{5}$ Cf. Ibid., p. 16.

${ }^{6}$ Cf. Ibid., p. 11.

${ }^{7}$ Cf. SHELDRAKE, Philip. Espiritualidade e teologia: vida cristã e fé trinitária. São Paulo: Paulinas, 2005, p. 53.

${ }^{8}$ Cf. SUDBRACK, Josef. Op., cit., p. 45 - 46.

${ }^{9}$ Ibid., p. 71.
} 
um olhar imbuído de discernimento ${ }^{10}$. Experiências alegadas como religiosas ineficazes ou até destrutivas refletem, consequentemente, uma espiritualidade comprometedora e conhecimentos inadequados do absoluto. ${ }^{11}$

Neste terreno movediço, da mística, torna-se clarificadora a contribuição da reflexão cristológico-trinitária para compreensão desta experiência religiosa. Com a intenção de contribuirmos para esta compreensão, é necessário conscientizarmo-nos da postura adequada que temos que tomar. Pois "sobre valores como a experiência mística, a espiritualidade e sobre a religião como sentido da vida, só podemos falar e argumentar de forma genuína a partir da nossa própria posição." 12 Partido deste pressuposto, abordando as feições da experiência mística Sudbrack esclarece:

Naturalmente, a busca cristã tem como medida Jesus Cristo, a palavra viva de Deus. Com isso as feições da experiência com Deus tornam-se mais visíveis, o que ajuda não só a revitalizar a própria religiosidade, mas também a entender mais profundamente as experiências místicas. ${ }^{13}$

Sudbrack reúne e elabora argumentos onde descreve esta mística como um encontro pessoal com o Absoluto, independente do nome que este receba, no caso cristão, o Deus Trinitário. O resultado deste encontro pessoal de mútuo amor em liberdade só é válido se revela o seu valor na ação concreta, isto é, do diálogo deste encontro deve florescer a verdadeira vida em amor. ${ }^{14}$ Assim, "Karl Rahner fala do cristão (devoto) que no futuro será um místico, ou não será mais cristão, dizendo que ele é uma pessoa que vivenciou uma experiência." ${ }^{15}$ Existe um consenso onde este encontro é referido como sendo "uma experiência de união ou comunhão com Deus (...). Podendo ser representada por diversas outras palavras ou imagens que remetem a esta realidade." 16

Mas em que consistia a experiência de Jesus de Nazaré com Deus? Como ele a experimentou? E como a descreveu? Nolan lembra que, todos os místicos relatam que as palavras ou imagens que nós utilizamos para descrever esta

\footnotetext{
${ }^{10}$ Cf. Ibid., p. 11.

${ }^{11}$ Cf. SHELDRAKE, Philip. Op., cit., p.30.

${ }^{12}$ SUDBRACK, Josef. Op., cit., p. 16 - 17.

${ }^{13}$ Ibid., p. 75.

${ }^{14}$ Cf. Ibid., p. 25 - 40.

${ }^{15}$ Ibid., p. 72.

${ }^{16}$ NOLAN, Albert. Jesus hoje: uma espiritualidade de liberdade radical. São Paulo: Paulinas, 2008, p.109 - 110 .
} 
experiência são inadequadas, nada podendo nos transmitir desta experiência desprovida de imagens e palavras. Porém Jesus, que era um místico, a experimentou como relação existente entre pai e filho e descrevendo-a falando a Deus e de Deus como seu abbá. E para compreendermos a experiência e a espiritualidade de Jesus, é necessário observar que o termo abbá exprime intimidade, sendo usado por ele como Deus que é mencionado como Pai amoroso que abraça, segura e protege o seu filho e filha com amor cordial e incondicional, que exerce o perdão incondicionalmente, no qual se pode confiar sem reservas. ${ }^{17} \mathrm{Em}$ sua jornada "Jesus via a si próprio como filho que aprendia imitando o próprio Pai." ${ }^{18}$ Assim, aprendia a perdoar incondicionalmente, a amar justos e injustos, mantendo esta postura tanto para amigos como para aqueles que o perseguiam(Mt 5, 45) ${ }^{19}$ Nolan prossegue utilizando a reflexão de Schillebeeckx:

Se acharmos difícil tomar Jesus a sério e viver como ele viveu, isso deve-se ao fato de ainda não termos experimentado Deus como nosso abbá. A experiência de Deus como seu abbá era a fonte da sabedoria de Jesus, do seu discernimento, da sua confiança e da sua radical liberdade. Sem isso é impossível compreender por que razão e de que forma ele fazia aquilo que fazia. ${ }^{20}$

\section{Reflexões sobre a espiritualidade a partir do contexto cristológico- trinitário}

Sem imposição, mas como proclamação, a doutrina cristã no seu aspecto cristológico-trinitário traz elementos que embasam uma compreensão global da espiritualidade, desempenhando um papel incalculável, nos levando a possibilidade de fugirmos de abstrações ${ }^{21}$.

O conhecimento que julgamos ter de Deus, certamente, norteará a experiência vivencial a ser buscada por todos aqueles que desejam fazer a vontade de Deus. Aqui se encontra a questão crucial. Pois, esta prática de vida pode ser orientada por uma teologia equívoca, imatura e até destrutiva para o verdadeiro ideal cristão ainda que esta teoria e práxis sejam tomadas com toda boa

\footnotetext{
${ }^{17}$ Cf. Ibid., p. 109 - 111.

${ }^{18}$ Ibid., p. 111.

${ }^{19}$ Cf. Ibid., p.11-12.

${ }^{20}$ SCHILLEBEECKX, Edward. Jesus: an experiment in christolgy. London: Collins, 1979, apud SHELDRAKE, Philip. 2005, p. 112.

${ }^{21}$ Cf. SUDBRACK, Josef. Op., cit., p. 75.
} 
fé e boa vontade. É notoriamente isso que vemos em diversos casos de fundamentalismo religioso e outros movimentos que tentam legitimar o comportamento baseado numa doutrina errônea de Deus. Neste momento torna-se esclarecedor o texto de Sheldrake:

Todas as afirmações humanas sobre Deus têm implicações práticas; vivemos aquilo que afirmamos. Espiritualidades ineficazes ou até destrutivas inevitavelmente refletem teologias inadequadas de Deus. Nesse sentido, a qualidade da espiritualidade é um teste da adequação da teologia de Deus que está por trás dela. A doutrina cristã de Deus procura manter um equilíbrio delicado de transcendência e imanência. $\mathrm{O}$ que governa o modo como entendemos e reagimos ao universo material. ${ }^{22}$

A doutrina de Deus deve ser alvo de profundas reflexões e seriedade, já que a mesma implicará diretamente na vida daquele (a) que por ela deseja guiar-se, sendo fundamental para a realidade da espiritualidade cristã. Quem assim acredita, por esta compreensão vive. O equilíbrio, coerência e profunda reflexão devem permear toda esta busca. Não podemos excluir nesta jornada a oração e devoção, para que as realidades que subjazem a mera contemplação humana sejam reveladas e clarificadas pela presença do Espírito de Deus.

A "Trindade é infinitamente frutífera e infinitamente criativa em sua própria vida interior. Esse dinamismo interior de Deus necessariamente prorrompe em criação e revelação." ${ }^{23}$

Sheldrake narrando a inspiração que Richard de St. Victo teve de Agostinho de Hipona, com relação à Trindade, esclarece:

Inspirado por Agostinho, Richard enfatiza que o amor era o centro das relações com Deus. Para ele, a perfeição do amor exigia não apenas o amor mútuo de duas pessoas, mas uma terceira pessoa com quem essa alegria do amor mútuo possa ser compartilhada (De Trinitate 3,19). O verdadeiro amor se expressa não na introspeção fechada de duas pessoas, mas no compartilhamento desse amor. Em um reflexo de Deus a Trindade como amor, o amor interpessoal humano é em essência autotranscendente, o que é causado especificamente pela ação do Espírito de Deus dentro do espírito humano (De Trinitate 6,14). O amor, portanto, está no âmago da vida cristã e é muito mais do que uma fonte de satisfação ou realização. Ele traz à existência uma comunidade baseada na comunicação e mutualidade. ${ }^{24}$

\footnotetext{
${ }^{22}$ SHELDRAKE, Philip. Op., cit., p.30.

${ }^{23}$ Ibid., p. 29.

${ }^{24}$ Ibid., p. 71-72.
} 
Logo, a partir desta relação de amor da comunidade divina e da espiritualidade humana, não pode haver prática de uma espiritualidade plena onde o amor não seja praticado.

Pensar em Deus como Trindade é afirmar uma sociedade ou relacionamentos dentro de Deus. Os seres humanos criados à sua imagem são chamados a compartilhar esta, compartilhando este amor com próximo, fracassando quaisquer comportamentos e ideologias individualistas a partir do Deus-emTrindade. ${ }^{25}$

Acompanhando Sheldrake é possível afirmar que a doutrina da Trindade é vital para a espiritualidade cristã. Toda espiritualidade autêntica é trinitária. Pelo alcance das implicações práticas, a Trindade constitui o coração e alma da espiritualidade cristã, sendo a pedra fundamental por sintetizar toda a "economia" do relacionamento de Deus com a criação e a humanidade. Relacionando-se com a abertura da humanidade à transcendência. É paradigma para a unidade de toda realidade. Como vocação da humanidade é sermos deificados, tornados como Deus, somos arrastados para dentro da própria comunidade de Pai, Filho e Espírito. ${ }^{26}$

O referencial Deus-Trindade deve ser a realidade para todos os cristãos que desejam realmente buscar uma espiritualidade global e integradora do homem com Deus, com a criação e com o próximo. E "o modo como os cristãos designam esse Deus, cuja própria vida é dar e revelar, é Trindade." ${ }^{27}$ Sendo a criação "o transbordamento da vida desse Deus." ${ }^{28}$ O modo de ser e de se relacionar do Deus-Trindade é o modo de como o ser humano deve interagir com a realidade a sua volta.

Para uma compreensão adequada deste Deus e sua revelação, é necessário entender que, "a questão crucial é a ligação íntima entre a natureza fundamental de Deus e Deus conforme revelado por meio da criação e salvação." ${ }^{29}$ Esta questão crucial só poderá ser respondida satisfatoriamente se compreendermos “o irrevogável compromisso de Deus com o mundo em Jesus Cristo. É isso que a doutrina da encarnação procura expressar." 30 Para isso, a encarnação convida à reflexão equilibrada entre transcendência e imanência de Deus; e no ser humano,

\footnotetext{
${ }^{25}$ Cf. Ibid., p. 31.

${ }^{26}$ Cf. Ibid., p. 33.

${ }^{27}$ Ibid., p. 8.

${ }^{28}$ Ibid., p.33.

${ }^{29}$ Ibid., p. 31.

${ }^{30}$ Ibid., p. 31.
} 
o equilíbrio entre corporeidade e espiritualidade, entre a entrega a Deus e engajamento social a serviço do próximo. É dentro desta compreensão que se deve construir uma espiritualidade autêntica. Neste contexto Sheldrake comenta:

Em termos cristãos, "espiritualidade" diz respeito a como as pessoas se apropriam do modo subjetivo de crenças tradicionais sobre Deus, a pessoa humana, a criação e seu inter-relacionamento, e então se expressam na adoração, nos valores básicos e no estilo de vida. Assim a espiritualidade é o todo da vida humana visto em termos de uma relação consciente com Deus, em Jesus Cristo, por meio da morada interior do Espírito (...). ${ }^{31}$

Compartilhando o que Sheldrake entende como implicação da realidade da encarnação para a compreensão do ser de Deus, e como essa compreensão de Deus se torna o referencial para a busca da espiritualidade:

A crença na encarnação também convida as pessoas a adotar uma abordagem equilibrada com a natureza humana e especialmente com sua dimensão material, o corpo. Isso não deve ser nem radicalmente pessimista nem otimista. A encarnação é mais que uma defesa da realidade e importância da natureza humana de Jesus Cristo. Ela é um princípio regulador da vida cristã; do modo como Deus se relaciona com o mundo e o modo como reagimos. O que significa que a visão cristã de Deus, e a auto-revelação de Deus, força a espiritualidade a atribuir uma importância fundamental à história humana e à existência material. ${ }^{32}$

A encarnação é o símbolo paradigmático de todo o relacionamento humano com toda realidade em sua volta. Jesus de Nazaré apresenta a concepção da imagem de Deus que é amor. O equilíbrio entre a imanência e a transcendência de Deus, demonstrando ao mesmo tempo um Deus totalmente outro, porém próximo do ser humano podendo ser chamado de Pai, $A b b a ́$, a cada momento ${ }^{33}$. Essa compreensão de Jesus o levava a buscar total ${ }^{34}$ comunhão com Deus, pois sabia que podia como uma criança ${ }^{35}$, confiar neste Deus, confiança até na hora da morte ${ }^{36}$. Isso gerava em Jesus uma total entrega

\footnotetext{
${ }^{31}$ Ibid., p. 53.

${ }^{32}$ Ibid., p. 31.

${ }^{33}$ Cf. NOLAN, Albert. Op., cit., p.148.

${ }^{34}$ Cf. Ibid., p.199.

${ }^{35}$ Cf. Ibid., p.173.

${ }^{36}$ Cf. Ibid., p.231.
} 
aos desígnios de Deus, amando a Deus e ao próximo de forma incondicional esvaziando-se para se preenchido da vontade de Deus.

A encarnação nos leva à nova dimensão sobre o ser de Deus e da espiritualidade, colocando-nos diante de uma realidade que regula a vida cristã em todas as suas dimensões. A auto-revelação de Deus em Cristo (encarnação) não permite que nenhuma dimensão da vida cristã deixe de ser regulada pelo paradigma de viver como Jesus viveu. Nesta concepção, Jesus não passa a ser visto apenas como um exemplo a ser seguido, mas como o referencial que revela a nossa vocação (escatológica).

Albert Nolan apresenta "quais os passos concretos que temos de dar (...) para vivermos no nosso tempo como Jesus viveu no dele." ${ }^{37}$ Nestes passos, podemos fundamentar a jornada humana para constituição da espiritualidade.

Em sua trajetória "Jesus chamava ao arrependimento ou à conversão, todavia a herança que ele deixou aos seus discípulos foi um caminho, uma estrada, um percurso." ${ }^{38}$ Caminho de crescimento espiritual que é um processo de transformação pessoal e social. Para Nolan, Jesus não teria falado em passos ou etapas para o crescimento espiritual, mas estes estariam induzidos em suas parábolas. A vida espiritual evolui, interagindo com pessoas, com acontecimentos históricos, com oportunidades, com mudanças e mutações ao longo deste caminho para atingirmos uma maturidade e consciência mais profunda e para uma radical liberdade. ${ }^{39}$ Pelos dados bíblicos e vivências humanas, não podemos negligenciar a afirmação: "ora, a revelação do Deus cristão é inseparável da experiência e práxis do ser humano." ${ }^{40}$ A experiência humana necessita caminhar na mutualidade com outras experiências pessoais e comunitárias e percorrer por acontecimentos históricos para atingir, dentro do que for possível, espiritualidade e conhecimento de Deus.

Deus como criador, compreende esta realidade referente a capacidade humana de apreensão de conhecimento e experiência. Assim, como Deus de

\footnotetext{
${ }^{37}$ Cf. Ibid., p 137-268.

${ }^{38}$ Ibid., p.137.

${ }^{39}$ Cf. Ibid., p. 137-138.

${ }^{40}$ BINGEMER, Maria Clara; FELLER, Vitor Galdino. Deus Trindade: a vida no coração do mudo. 2 ed. São Paulo:Paulinas; Valência ESP: Siquem, 2009.(Coleção livros práticos de teologia; 6), p. 33. Neste segundo capítulo, "O Deus da Bíblia", aborda-se a auto-revelação de Deus na história do povo de Israel, as etapas pré-cristãs, e as compreensões desta auto-revelação. A retomada e releitura cristã das quatro etapas e a auto-revelação de Deus no Novo Testamento em Jesus de Nazaré, não mais uma etapa, mas síntese, que embora inserida na tradição do Antigo Testamento, em Jesus revelará uma novidade radical a respeito de Deus (Cf. pp. 33-62).
} 
amor, não viola esta característica humana, mas se auto-revela respeitando esta dimensão da sua criação. Basta lembrarmo-nos das palavras de Jesus:

Ainda tenho muito que vos dizer, mas vós não o podeis suportar agora. Mas, quando vier aquele, o Espírito da verdade, ele vos guiará a toda a verdade; porque não falará de si mesmo, mas dirá tudo o que tiver ouvido, e vos anunciará o que há de vir. ${ }^{41}$

Aqui, observamos o profundo conhecimento e respeito de Jesus pela limitação humana de apreensão da realidade, da espiritualidade e do ser e do agir de Deus, que apenas irá se concretizando com o caminhar histórico e profunda reflexão, ainda assim, esta apreensão só será possível com auxílio do Espírito de Deus. A espiritualidade de Jesus é transpassada por uma ação pneumatológica que capacita o crente em sua jornada.

Será necessário seguir a orientação do próprio Jesus e absorver "algumas das mudanças ou mutações que teríamos de considerar ao longo da estrada"42, em nossa própria conduta e consciência, para visualizarmos novos paradigmas para nossa espiritualidade. Nesta jornada "não percorremos sozinhos esta e outras vias semelhantes de transformação pessoal. A única forma de avançarmos será fazendo-o juntos... e curando-nos mutuamente." ${ }^{43}$

Esta espiritualidade envolve-se em compreender as diversas dimensões desfavoráveis da existência humana. O sofrimento, principalmente sem sentido, faz o ser humano clamar a Deus e até duvidar dele. ${ }^{44}$ Em mentes sensíveis pergunta-se pelo sentido da vida. Neste âmbito a reflexão sobre a cruz é esclarecedora, revelando-nos a realidade do sofrimento e da morte. Encorajando-nos ao enfrentamento dos embates da vida e à esperança. $\mathrm{Na}$ reflexão de Moltmann "Deus entregou seu filho "por nós" para ser tornar irmão de todos os abandonados e os reconduzir a Deus." ${ }^{45}$ Assim, "o sofrimento de Cristo não é exclusivamente sofrimento seu, mas é inclusive nosso sofrimento e o sofrimento de nossos dias." ${ }^{46}$ Sheldrake aponta a relação entre Jesus de Nazaré e a cruz:

\footnotetext{
${ }^{41}$ Jo $16,12-13$.

${ }^{42}$ NOLAN, Albert. Op., cit., p. 138.

${ }^{43}$ Ibid., p.138.

${ }^{44}$ Cf. MOLTMANN, Jürgen. Quem é Jesus para nós hoje? Petrópolis: Vozes, 1996, p. 33.

${ }^{45}$ Ibid., p.39.

${ }^{46}$ Ibid., p.42.
} 
Além disso, em termos de auto-revelação de Deus, é impossível evitar a conexão íntima entre a vida e o ministério de Jesus de Nazaré e a cruz de Jesus. A vulnerabilidade e impotência da cruz é um desafio radical a uma ênfase desequilibrada na glória de Deus. Ela desafia igualmente a falta de sentido e desesperança finais do sofrimento humano. A entrega, mutualidade e interdependência no próprio âmago da Trindade é revelada na cruz. Aqui somos convidados a perceber que o amor e a vulnerabilidade na entrega de Deus, e não as definições humanas de poder, são o que nos transforma e transforma o mundo. ${ }^{47}$

Ainda sobre a cruz de Jesus de Nazaré Sheldrake continua:

Sem negar a realidade do sofrimento, Deus revelado na cruz nos oferece a esperança de atingir a plenitude da humanidade. Chegamos a compartilhar a glória de Deus por meio, e não meramente a despeito, das vivências de, aparentemente, lidar com a morte na vida. Uma teologia e espiritualidade que desviam da cruz não terão muita coisa a dizer sobre a real presença de Deus no sofrimento, fracasso e pecado humanos. Essas realidades tornam-se intoleráveis. Por consequência, elas são ignoradas por algumas espiritualidades excessivamente otimistas. Seu principal papel parece ser proteger as pessoas da possibilidade de desespero final. ${ }^{48}$

Moltmann nos diz que, "toda angústia humana é no fundo, isto é desde o nascimento, medo (angústia) da separação. A angústia traz a solidão. A angústia isola, emudece." ${ }^{49}$ Relacionando a angústia de Cristo e a humana menciona que "na fé cristã a angústia não separa de Deus, pelo contrário, ela conduz a uma comunhão com Deus cada vez mais profunda." ${ }^{50}$ Sendo a fé cristã em Deus comunhão com o cristo injuriado, sofredor , abandonado, o ser humano na sua angústia participa da angústia de Cristo, pois Cristo suportou na sua dor as angústias que sobrevêm ao ser humano, tornando-se assim, o consolador da angústia.$^{51}$ Porém, existe superação da angústia dos sofrimentos humanos? Para Moltmann não podemos superá-la. Somos arrancados dela não por um superpoder de um Cristo celeste, mas por um Cristo terreno e humano. Somos libertados de nossas aflições pelas aflições de Cristo, sendo os

\footnotetext{
${ }^{47}$ SHELDRAKE, Philip. Op., cit., p. 31-32.

${ }^{48}$ Ibid., p. 32.

${ }^{49}$ MOLTMANN, Jürgen. Op., cit., p.55.

${ }^{50}$ Ibid., p.55.

${ }^{51}$ Cf. Ibid., p.55.
} 
nossos ferimentos curados paradoxalmente por outros ferimentos, conforme referido sobre o servo de Javé (Isaías 53). ${ }^{52}$

Os sofrimentos humanos de dor, fraqueza e solidão na angústia da separação culminam na experiência do abandono, assim como a experiência de Cristo:

O que Cristo experimenta na sua angústia, no Getsêmani, é a condensação desta angústia ilimitada, que consciente ou inconscientemente todos os homens têm. Ele é o mais injuriado de todos, pois ele sofreu a angústia do abandono de Deus, que todos os outros seres humanos podem sentir, mas não podem suportar na realidade. Quem sente na sua angústia esse abandono de Deus experimenta uma "tristeza nos moldes de Deus" (2 Cor 7,10). Ele participa da dor e angústia de Cristo, justamente porque Cristo suportou essa angústia que pode atingir a ele. Na sua cruz ele se confia a Cristo injuriado. Na imagem do crucificado, a sua angústia indefinida ganha uma conformação com a qual ele pode se identificar, porque ele descobre nela sua própria e plena miséria. Essa é a cristologia da conformidade do "Cristo conosco", de Cristo nosso irmão, que está no caminho na angústia, na tentação, na prisão, no desprezo, no abandono de Deus. ${ }^{53}$

Cristo morrendo em nosso lugar e por nós, suportando tudo o que me angustiava e ameaçava, torna o crente não apenas solidário com o destino de Cristo, mas o conduz, principalmente, a uma atitude de gratidão liberta da angústia. Liberta-me, também da angústia de ter angústia e me dá uma identidade incorruptível nele. De tal modo sou arrancado da angústia que ela se separa de mim e sua ameaça desmorona. ${ }^{54}$ Desta forma, "ser arrancado da angústia significa levantar-se da angústia e resistir a ela: atravessá-la livremente." ${ }^{55}$

Devemos ter em mente que "a encarnação é a plenitude da manifestação de Deus e a plenitude da manifestação do homem. ${ }^{" 56} \mathrm{E}$ ainda :

A encarnação não deve ser pensada somente à luz de Jesus de Nazaré, sárquico, participante de nossas limitações e fragilidades, mas deve ser completada à luz da Ressurreição, onde se revelou, em sua total patência e

\footnotetext{
${ }^{52}$ Cf. Ibid., p.56.

${ }^{53}$ Ibid., p. 56 - 57.

${ }^{54}$ Cf. Ibid., p. 57 - 58.

${ }^{55}$ Ibid., p. 59.

${ }^{56}$ BOFF, Leonardo. Jesus Cristo Libertador: ensaios de cristologia crítica para o nosso tempo. Petrópolis: Vozes, 1986. p. 143.
} 
transparência, o que se escondia em Jesus de Nazaré: a universal e máxima abertura para toda a realidade cósmica, humana e divina a ponto de Paulo poder confessar Jesus ressuscitado "tudo em todas as coisas" $(\mathrm{Cl} \mathrm{3}, 11) .{ }^{57}$

A encarnação não revela apenas uma mensagem concernente a Jesus, mas também revela à natureza e o destino de cada homem, quem é Deus que em Jesus Cristo vem ao nosso encontro semelhante a nós respeitando nossa alteridade nos assume e repleta de sua divina realidade. ${ }^{58}$

\section{Concluindo com aproximações para o diálogo inter-religioso}

Apresentados alguns elementos da reflexão cristológico-trinitária, acreditamos que os mesmos podem contribuir para compreensão das experiências religiosas e da espiritualidade, e que estas devem ter como proposta tornar o ser humano mais humano e cônscio do sentido último da sua existência, sendo este critério usado como aproximação para o debate inter-religioso. E neste diálogo encontrar elementos que favoreçam este propósito, mesmo não pertencendo a um dos lados, deve ser observado a sua contribuição e, encontrados antagônicos, estes devem ser um desafio a ser superado.

O intento é que, os frutos deste diálogo colaborem para mútua compreensão religiosa e, contribuindo consequentemente, para a paz entre as religiões, justiça e paz na Terra. Pois conscientemente sabemos que somente haverá paz entre as nações havendo paz entre as religiões e entre estas, a paz somente poderá ser estabelecida por intermédio do diálogo (...). ${ }^{59}$

Para uma humanidade melhor será necessário a transformação da consciência individual e coletiva, num despertar de forças espirituais pela reflexão, medição, oração e pelo pensamento positivo, numa conversão de corações, dispostos a correr riscos e aceitar sacrifícios. Todos estão convidados a esta postura, sejam religiosos ou não. ${ }^{60}$

Cristãos, budistas, islâmicos, hinduístas e todos os outros religiosos que realmente buscaram que buscam e os que ainda anseiam vivenciar a experiência religiosa e a espiritualidade, não podem "pretender compreender o

\footnotetext{
${ }^{57}$ Ibid., p.146.

${ }^{58}$ Cf. Ibid., p.151.

${ }^{59}$ Cf. KÜNG, Hans. Para que um ethos mundial? Religião e ética em tempos de globalização. Conversando com Jürgen Hoeren. São Paulo: Loyola. 2005, p. 9.

${ }^{60}$ Ibid., p. 190.
} 
Incompreensível nem conhecer o Inescrutável" ${ }^{61}$. Assim, conforme Paulo ${ }^{62}$, só podemos conhecer "a verdade, que é Deus, apenas como em um espelho ou enigma, parcialmente e em diversos fragmentos, sempre segundo nossa especial situação de cada momento." ${ }^{63}$ Estamos conscientes do caminhar dos seres humanos e que, "a cristandade está 'in via', a caminho: 'Ecclesia peregrinans', 'homines viatores'. E não estamos sozinhos no caminho, mas acompanhados por milhões de pessoas de todas as confissões e religiões, que seguem seu próprio caminho." ${ }^{\circ 4}$

Nestas condições "todos deveríamos estar dispostos de maneira ilimitada a aprender, a acolher algo da verdade dos outros e a comunicar generosamente a própria verdade." ${ }^{\prime 65} \mathrm{E}$ devido as dificuldade das diferenças de cultura e linguagem, como agente moderador deste diálogo, o amor deve entrar onde o entendimento fica de fora. ${ }^{66}$

A abertura ao diálogo "às outras religiões não exigem a suspensão, nem da própria convicção de fé, nem da questão da verdade. Devemos lutar - numa "luta fraterna" (Vaticano II: "fraterna aemulatio") - pela verdade." 67

\section{Referências Bibliográficas}

BINGEMER, Maria Clara; FELLER, Vitor Galdino. Deus Trindade: a vida no coração do mudo. 2 ed. São Paulo:Paulinas; Valência ESP: Siquem, 2009.(Coleção livros práticos de teologia;6)

BOFF, Leonardo. Jesus Cristo Libertador: ensaios de cristologia crítica para o nosso tempo. Petrópolis: Vozes, 1986.

KÜNG, Hans. Para que um ethos mundial? Religião e ética em tempos de globalização. Conversando com Jürgen Hoeren. São Paulo: Loyola. 2005. . Teologia a caminho: fundamentação para o diálogo ecumênico. São Paulo: Paulinas, 1999.

MOLTMANN, Jürgen. Quem é Jesus para nós hoje? Petrópolis: Vozes, 1996.

${ }^{61}$ KÜNG, Hans. Teologia a caminho: fundamentação para o diálogo ecumênico. São Paulo: Paulinas, 1999, p. 290.

${ }^{62}$ Cf. 2 Coríntios 13,12.

${ }^{63}$ Ibid., p. 290.

${ }^{64}$ Ibid., p. 290.

${ }^{65}$ Ibid., p. 291.

${ }^{66}$ Cf. SUDBRACK, Josef. Op., cit., p. 125.

${ }^{67}$ KÜNG, Hans. Op., cit., p. 290. 
NOLAN, Albert. Jesus hoje: uma espiritualidade de liberdade radical. São Paulo: Paulinas, 2008.

SCHILLEBEECKX, Edward. Jesus: an experiment in christolgy. London: Collins, 1979.

SHELDRAKE, Philip. Espiritualidade e teologia: vida cristã e fé trinitária. São Paulo: Paulinas, 2005.

SUDBRACK, Josef. Mística: a busca do sentido e a experiência do absoluto. São Paulo: Loyola, 2007.

Ismael Souza

Bacharel em Teologia

Licenciatura e Especialização em Filosofia Bacharelado e Licenciatura em Educação Física Mestrando em Teologia Sistemático-Pastoral pela PUC-RIO

Artigo Recebido em 26/08/2011 Artigo Aprovado em 30/11/2011 